\title{
Renal Cortical Thickness After Pyeloplasty in Pediatric Ureteropelvic Junction Obstruction
}

\section{Virote Chalieopanyarwong Worapat Attawettayanon}

Division of Urology, Department of Surgery, Faculty of Medicine, Songklanagarind Hospital, Prince of Songkla University, Songkhla, Thailand
Correspondence: Worapat

Attawettayanon

Division of Urology, Department of Surgery,

Faculty of Medicine, Songklanagarind

Hospital, Prince of Songkla University,

Songkhla, 90II0, Thailand

Tel +667-445-1428

Email aworapat@medicine.psu.ac.th
Purpose: The main goal of pyeloplasty is to maintain or improve renal function. Diuretic renography is the gold standard for evaluating renal function after pyeloplasty. Renal ultrasonography (RUS) is commonly used to determine hydronephrosis in pediatric patients. We hypothesized that the change in the renal parenchymal cortex would predict pyeloplasty success. In this study, we aim to measure renal cortical thickness change after pyeloplasty in ureteropelvic junction obstruction patients.

Materials and Methods: We retrospectively reviewed 38 patients who underwent pyeloplasty between 2005 and 2019. We divided patients into three age groups and compared the difference of renal parenchymal thickness change by using generalized estimating equations to identify associated factors for renal cortical thickness change after pyeloplasty.

Results: Thirty-nine kidney units were identified. The median age at the time of surgery was $41.61 \pm 40.99$ months. Generalized estimating equations showed significant change of renal parenchymal thickness over the period of follow-up $(p=0.02)$. The estimate of thickness change was $0.0373 \mathrm{~mm} / \mathrm{month}$. Age at the time of surgery was not associated with significant renal cortical thickness over the period of follow-up. The positive predictive factors for renal cortical thickness were creatinine clearance, pre-operative anteroposterior diameter and preoperative renal differential function. The negative factors for decrease of renal cortical thickness were body weight, presentation with abdominal mass, and history of infection.

Conclusion: Renal cortical thickness after pyeloplasty was improved over the period of follow-up. Age at surgery was not associated with improvement of renal parenchymal thickness.

Keywords: ureteropelvic junction obstruction, renal parenchymal thickening, ultrasonography, hydronephrosis

\section{Introduction}

Ureteropelvic junction obstruction (UPJO) is the most common cause of pediatric hydronephrosis $(\mathrm{HN}) .^{1,2}$ The condition is diagnosed from various presentations and ages. The pathological causes of UPJO are not well known, and include both extrinsic and intrinsic factors. If untreated, severe $\mathrm{HN}$ patients may develop clinical deterioration such as urinary tract infections (UTI), hematuria, decline in renal function, and permanent kidney damage. ${ }^{3}$ Approximately $20-50 \%$ of pediatric patients will end up with surgical treatments. ${ }^{4}$ The long-term success rate of surgical correction with Anderson- Hynes pyeloplasty is more than $95 \%$. 56 Pyeloplasty is slowly changing from open to minimally invasive (laparoscopic and robotic), which seems to be safe, efficient, and guarantee adequate outcomes. ${ }^{7}$ 
The main goals of treatment are to relieve symptoms and maintain or improve renal function. ${ }^{8}$ Therefore, early detection and careful clinical evaluation may prove beneficial for those patients. Renal ultrasonography (RUS) is non-invasive, free from radiation effects, and is the most commonly used method to study $\mathrm{HN}$ in pediatric urologic patients. However, RUS is not the gold standard imaging study for evaluation after surgery. Currently, diuresis renography with technetium Tc $99 \mathrm{~m}$ diethylene triamine pentaacetic acid (DTPA) and technetium Tc $99 \mathrm{~m}$ mercaptoacetyltriglycine (MAG-3) is commonly used to determine the success of surgery. ${ }^{9,10}$ Diuresis renography has a significant associated cost and is not available in some centers. A review of the current published data fails to yield a consensus on the ideal post-pyeloplasty radiological follow-up in the pediatric population. ${ }^{11,12}$ Several studies have reported improved renal cortical thickness that reflects renal function after pyeloplasty. ${ }^{13,14}$ Hence, in this study, we aim to determine renal cortical thickness change after pyeloplasty in UPJO patients. The secondary objective is to determine a correlation between age at surgery and renal parenchymal thickness change after pyeloplasty.

\section{Materials and Methods}

This study was conducted at the urology department of a tertiary hospital. All cases were diagnosed by MAG-3 lasix renography and ultrasonography. The indications for surgery included: Increasing of antero-posterior (AP) diameter on ultrasonography, low or decreasing differential renal function, and breakthrough infection. We reviewed data of ureteropelvic junction obstruction patients that received dismember pyeloplasty from 2005 to 2019 . We used ICD 9 CM code 55.87 to identify ureteropelvic junction obstruction patients. We included patients under 15 years old who had both pre-operative and post-operative ultrasonography. If patients were older than 15 years old, missing ultrasonography pre- and post-operative, loss to follow-up, or evidence of ureterovesical junction obstruction or vesicoureteral reflux were excluded from this study. The pre-operative data included gender, body weight, height, presentation of disease, kidney disease side, associated abnormality of KUB system, history of infection, indication of surgery, date at diagnosis and surgery, serum BUN, and creatinine. Pre-operative and post-operative renal ultrasonography information recorded maximum renal parenchymal thickness and AP diameter of the renal pelvis. Open pyeloplasty was performed by two senior urologists in our institute. Renal ultrasonography was performed by a pediatric radiologist to measure anteroposterior pelvic diameter, parenchymal thickness. Diuretic renography was used to diagnose UPJO and showed differential renal function.

We hypothesized that renal thickness would increase after the surgery. Assuming that the standard deviation of cortical thickness is three times the error, with a significance level set at $<0.05$, the required sample size would be 35 . Statistical analysis used $\mathrm{R}$ software Version 3.5.1 to determine the mean and standard deviation from demographic data. Since the subjects were measured more than once, instead of ordinary $t$-test or linear regression, Generalized estimating equations (GEE) were employed to predict the change in each subgroup.

\section{Results}

\section{Clinical Characteristics of Patients}

There were 65 cases from 2005 to 2019. After excluding patients without pre-operative or post-operative RUS, a total of 38 cases were included in this study. All patients received Anderson-Hynes dismembered pyeloplasty and renal pelvic reduction without internal ureteral stent. Three quarters were male and two thirds had an affected left side. Nearly $50 \%$ of patients were diagnosed from antenatal ultrasonography and the other half presented with UTI, abdominal mass, or abdominal pain (Table 1). The most commonly associated urinary system abnormality was bilateral UPJO and two kidney units were performed in bilateral disease patients, with the second operation a year after the first. There were 24 kidney units performed through pyeloplasty without associated urinary system abnormality. Nearly two thirds of the patients had no UTI before undergoing pyeloplasty. The most common indication for pyeloplasty was UTI in 15 kidney units, followed by renal deterioration, abdominal mass, and abdominal pain.

Pre-operative RUS displayed a renal parenchymal thickness of $5.51 \mathrm{~mm}$ and $41.32 \mathrm{~mm}$, and a $41.32 \mathrm{~mm}$ anteroposterior renal pelvic diameter in the affected kidney. The mean renal differential function in the disease side was $44.7 \%$ (Table 2).

\section{Pre-Operative Predictors for Improvement of Parenchymal Thickness}

Renal parenchymal thickness was improved over the follow-up time (Figure 1). Time to intervention was not 
Table I The Patients' Characteristics of 39 Renal Units

\begin{tabular}{|c|c|}
\hline Variables & $\begin{array}{l}\text { No. of Renal } \\
\text { Units }\end{array}$ \\
\hline \multicolumn{2}{|l|}{ Sex } \\
\hline Boys & 29 \\
\hline Girls & 10 \\
\hline \multicolumn{2}{|l|}{ Affected side } \\
\hline Left & 26 \\
\hline Right & 13 \\
\hline \multicolumn{2}{|l|}{ Presentation } \\
\hline Prenatal ultrasound & 17 (43.6\%) \\
\hline Urinary tract infection & $10(25.6 \%)$ \\
\hline Abdominal mass & $9(23.0 \%)$ \\
\hline Abdominal pain & $3(7.8 \%)$ \\
\hline \multicolumn{2}{|l|}{ Associated abnormality } \\
\hline No & 24 \\
\hline Bilateral UPJO & 12 \\
\hline Bilateral VUR & 1 \\
\hline Duplex kidney & I \\
\hline Multicystic dysplastic kidney & 1 \\
\hline \multicolumn{2}{|l|}{ History of infection } \\
\hline No & 23 \\
\hline I time & 12 \\
\hline 2 times & 2 \\
\hline$>2$ times & I \\
\hline No data & I \\
\hline \multicolumn{2}{|l|}{ Indication for surgery } \\
\hline Infection & 15 \\
\hline Renal deterioration & 13 \\
\hline Abdominal mass & 8 \\
\hline Abdominal pain & 3 \\
\hline Age at diagnosis in months, mean (SD) & $31.51(42.91)$ \\
\hline Age at surgery in months, mean (SD) & 41.61 (40.99) \\
\hline Body weight in kg, mean (SD) & $15.32(9.07)$ \\
\hline Height in $\mathrm{cm}$, mean (SD) & $93.10(23.47)$ \\
\hline Body mass index, mean (SD) & $16.92(2.86)$ \\
\hline Blood urine nitrogen in $\mathrm{mg} \%$, mean (SD) & $13.59(4.80)$ \\
\hline Creatinine in $\mathrm{mg} / \mathrm{dL}$, mean (SD) & $0.37(0.16)$ \\
\hline $\begin{array}{l}\text { Creatinine clearance in } \mathrm{mL} / \mathrm{min} / 1.73 \mathrm{~m}^{2,} \text { mean } \\
(\mathrm{SD})\end{array}$ & $78.03(24.46)$ \\
\hline
\end{tabular}

Abbreviations: UPJO, ureteropelvic junction obstruction; UVJO, ureterovesical junction obstruction; VUR, vesicoureteral reflux.

correlated with improvement of cortical thickness (Table 3). High baseline values of creatinine clearance, antero-posterior diameter were associated with increasing
Table 2 Pre-Operative Renal Ultrasonography and Diuretic Renography of 39 Renal Units

\begin{tabular}{|l|c|c|c|c|}
\hline \multirow{2}{*}{ Variables } & \multicolumn{2}{|c|}{ Disease Side } & \multicolumn{2}{c|}{$\begin{array}{c}\text { Contralateral } \\
\text { Side }\end{array}$} \\
\cline { 2 - 5 } & Mean & SD. & Mean & SD. \\
\hline $\begin{array}{l}\text { enal parenchymal thickness } \\
(\mathrm{mm})\end{array}$ & $5.5 \mathrm{I}$ & 2.54 & 9.20 & 3.88 \\
\hline $\begin{array}{l}\text { Anteroposterior pelvic } \\
\text { diameter (mm) }\end{array}$ & 41.32 & 24.01 & 8.21 & 7.15 \\
\hline Renal differential function (\%) & 44.73 & 12.86 & 55.26 & 12.86 \\
\hline
\end{tabular}

of renal parenchyma, while body weight and history of infection decreased renal parenchymal thickness (Table 4).

\section{Discussion}

Among our patients, renal parenchyma increased over time after pyeloplasty. Predictors for improvement of thickness included high baseline values of creatinine clearance, antero-posterior diameter. On the other hand, predictors for reduction of renal parenchymal thickness were body weight and history of infection.

The improvement of renal cortical thickness may be an indirect sign of post-operative success and improvement of renal function. After the obstruction was corrected, renal function could recover, especially in patients with good baseline pre-operative renal function. The return of kidney function may correlate with nephron mass, as determined by cortical thickness. ${ }^{15,16}$ Renal biopsy has been used by Huang et $\mathrm{al}^{17}$ to predict the ability of the recovery. Sclerotic glomeruli was found to be associated with severe injury of the kidney and reduction in renal function. In this study we did not perform any biopsy because we considered that this invasive procedure was unnecessary in routine practice.

Time to intervention is difficult to address. We found that time to intervention does not associate with cortical thickness change. A systematic review by Castagnetti et al ${ }^{11}$ reported that improvement of surgical outcome seemed unrelated to age of surgery. They found that pre-operative renal function was a predictor for improved surgical outcome. In our report, patients with good creatinine clearance, small pre-operative anteroposterior diameter and good preoperative renal differential function have positive progression of renal cortical thickness. Our report concedes with that of Harraz et al. ${ }^{13}$ They found the most important predictors for improved renal function after pyeloplasty were 


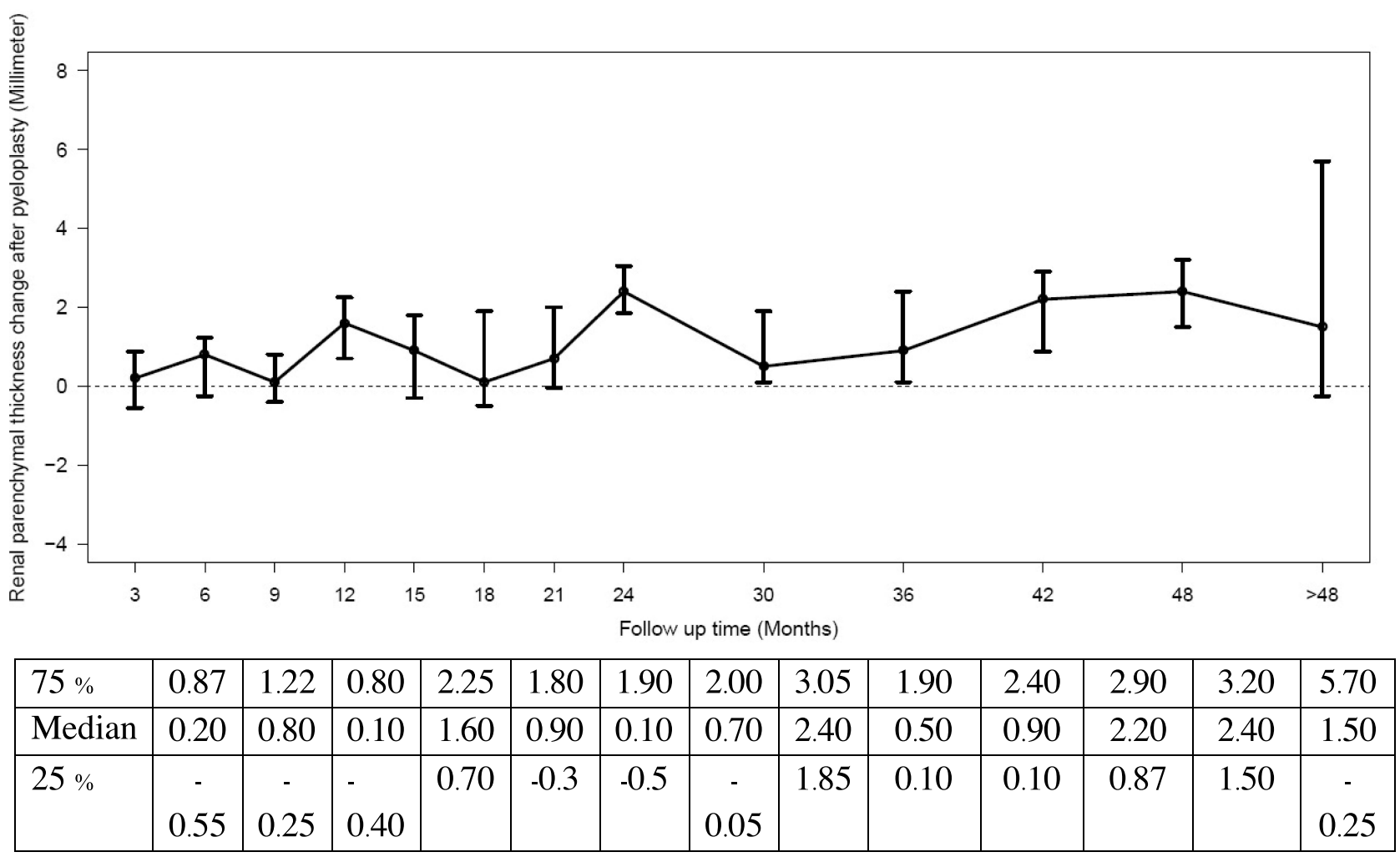

Figure I Median and IQR of renal parenchymal thickness change after pyeloplasty in 39 kidney units during the follow-up period. It summarizes the Generalized Estimating Equations (GEE) and shows renal parenchymal thickness improved over the period of follow-up. It was significantly increased in 24 months ( 2.4 mm IQR=I.85-3.05) and 48 months $(2.4 \mathrm{~mm}$ IQR=I.5-3.2).

baseline split renal function and cortical renal thickness. Kern et $\mathrm{al}^{10}$ also reported post-operative increasing in renal parenchymal to collecting system area with ratio $\geq 0.48$ and has a $100 \%$ positive predictive value for pyeloplasty success.

Various findings of ultrasound such as downgrading of anterior-posterior pelvic diameter and parenchymal to pelvic ratio were described as predictors for surgical outcomes. Han et $\mathrm{al}^{18}$ reported that high ratio of hydronephrosis area to renal parenchyma mass was a predictor for poor outcome. Kern et $\mathrm{al}^{10}$ showed that changing of renal parenchymal to collecting system area ratio (RPCSR) from pre-operative were the best predictor for pyeloplasty success. Almodhen et $\mathrm{al}^{19}$ showed that reduction of anterior-posterior pelvic diameter could reflect the success of an operation. However, early improvement on ultrasound could also be due to renal pelvic reduction rather than real improvement. The ratio of renal parenchymal and collecting system area may be a useful method for those patients.

Urine biomarkers such as neutrophil gelatinaseassociated lipocalin (NGAL), monocyte chemotactic peptide-1 (MCP1) are several potential predictors for post-operative outcomes. Both biomarkers were elevated in surgical patients and will decrease to a normal level after 3-12 months of surgery. ${ }^{20,21}$ We did not have

Table 3 Generalized Estimating Equations (GEE) of Renal Parenchymal Thickness Changed by Time of Follow-Up and by Age at Surgery

\begin{tabular}{|l|c|c|c|}
\hline & Estimate Thickening Change $(\mathbf{m m})$ & Std Err & p-value \\
\hline Time of follow-up & 0.0373 & 0.0168 & $0.02 *$ \\
Age at surgery $\leq$ I year old & 0.3314 & 0.5123 & 0.52 \\
Age at surgery I-5 years old & 0.0461 & 0.5001 & 0.93 \\
Age at surgery $>$ 5 years old & 0.6377 & $0.446 \mathrm{I}$ & 0.15 \\
\hline
\end{tabular}


Table 4 Generalized Estimating Equations (GEE) of Factors Related to Renal Parenchymal Thickness Change Along with Time of Follow-Up

\begin{tabular}{|l|c|c|c|}
\hline \multicolumn{1}{|c|}{ Estimated Thickening Change (mm) } & Std Err & p-value \\
\hline Factor & \multicolumn{3}{|c|}{} \\
\hline Sex (male) & 0.0417 & 0.2780 & 0.88 I \\
Creatinine clearance & 0.0221 & 0.0067 & 0.00 * $^{*}$ \\
Pre op differential function & 0.0249 & 0.0121 & $0.039^{*}$ \\
Pre op APD & 0.0166 & 0.0083 & $0.047^{*}$ \\
Body weight & -0.1063 & 0.0360 & $0.003^{*}$ \\
History of infection (yes) & -0.8817 & 0.4045 & $0.029^{*}$ \\
Presented with mass & -1.6902 & 0.8081 & $0.036^{*}$ \\
Underlying disease (yes) & -0.1713 & 0.3425 & 0.617 \\
\hline
\end{tabular}

Notes: *Significant. Generalized Estimating Equations (GEE) predicting factors related to renal parenchymal thickness. Positive factors included Creatinine clearance, preoperative anteroposterior diameter, and pre-operative renal differential function. The factors that decreased renal parenchymal thickness were body weight, presentation with abdominal mass, and history of infection.

Abbreviation: APD, anteroposterior diameter.

available data on urine markers. We hope it will be a strong available predictor in the future.

There are several limitations in our study. We did not have the data on changes of renal function. Variation in types of urinary diversion such as stent-less, JJ stent, or nephrostomy tube may have effects on the renal function outcome. Although our study is a small and retrospective review, we believe this outcome may be an essential study to develop a concept of time to follow-up and renal function improvement after pyeloplasty. The concept of using renal cortical thickness changing to predict operation outcome should be investigated by future larger studies.

\section{Conclusions}

Our small study suggested that the renal parenchymal cortex could gain thickness after pyeloplasty, especially among those with good baseline renal function parameters.

\section{Ethical Approval}

Review of medical records were performed without reconsent, which was approved by the Human Research Ethical Committee of the Faculty of medicine, Prince of Songkla University (Approval number: REC. 61-263-101). After data sheet fill-up, data were anonymously analyzed. All patients identities were protected in the whole process of analysis and manuscript preparation, which was in compliance with the Declaration of Helsinki.

\section{Disclosure}

The authors report no conflicts of interest in this work.

\section{References}

1. van der Toorn F, van den Hoek J, Wolffenbuttel KP, Scheepe JR. Laparoscopic transperitoneal pyeloplasty in children from age of 3 years: our clinical outcomes compared with open surgery. $J$ Pediatr Urol. 2013;9(2):161-168. doi:10.1016/j.jpurol.2012.01.007

2. Tipton T, Edwards K, Simpson K, Prasad M, Stec A. Pathologic Specimens at Time of Pyeloplasty: frequency and Practice Patterns. Urology. 2018;122:158-161. doi:10.1016/j.urology.2018.08.036

3. Li B, McGrath M, Farrokhyar F, Braga LH. Ultrasound-Based Scoring System for Indication of Pyeloplasty in Patients With UPJO-Like Hydronephrosis. Front Pediatr. 2020;8:353. doi:10.3389/fped.2020.00353

4. Liu X, Huang C, Guo Y, Yue Y, Hong J. Comparison of DJ stented, external stented and stent-less procedures for pediatric pyeloplasty: a network meta-analysis. Int J Surg. 2019;68:126-133. doi:10.1016/j. ijsu.2019.07.001

5. Song SH, Park S, Chae SY, Moon DH, Park S, Kim KS. Predictors of Renal Functional Improvement After Pyeloplasty in Ureteropelvic Junction Obstruction: clinical Value of Visually Assessed Renal Tissue Tracer Transit in ${ }^{99} \mathrm{~m}$ Tc-mercaptoacetyltriglycine Renography. Urology. 2017;108:149-154. doi:10.1016/j. urology.2017.05.044

6. O'Reilly PH, Brooman PJ, Mak S, et al. The long-term results of Anderson-Hynes pyeloplasty. BJU Int. 2001;87:287-289. doi:10.1046/j.1464-410x.2001.00108.x

7. Song SH, Lee C, Jung J, et al. A comparative study of pediatric open pyeloplasty, laparoscopy-assisted extracorporeal pyeloplasty, and robot-assisted laparoscopic pyeloplasty. PLoS One. 2017;12(4): e0175026. doi:10.1371/journal.pone. 0175026

8. Goetz G, Klora M, Zeidler J, et al. Surgery for pediatric ureteropelvic junction obstruction comparison of outcomes in relation to surgical technique and operating discipline in Germany. Eur J Pediatr Surg. 2019;29:33-38. doi:10.1055/s-0038-1668149

9. Lam W, Fernando A, Issa R, et al. Is routine postoperative diuresis renography indicated in all adult patients after pyeloplasty for ureteropelvic junction obstruction? Urology. 2015;85:246-251. doi:10.1016/j.urology.2014.09.033

10. Kern AJM, Schlomer BJ, Timberlake MD, Peters A, Hammer MR, Jacobs MA. Simple visual review of pre- to post-operative renal ultrasound images predicts pyeloplasty success equally as well as geometric measurements: a blinded comparison with a gold standard. J Pediatr Urol. 2017;13:401.e1-401.e7. 
11. Castagnetti M, Novara G, Benjamin F, Vezzu B, Rigamonti W, Artibani W. Scintigraphic renal function after unilateral pyeloplasty in children: a systematic review. BJU Int. 2008;102(7):862-868.

12. Psooy K, Pike J, Leonard M. Long-term followup of pediatric dismembered pyeloplasty: how long is long enough? $J$ Urol. 2003;169:1809-1812. doi:10.1097/01.ju.0000055040.19568.ea

13. Harraz AH, Helmy T, Taha DE, et al. Changes in differential renal function after pyeloplasty in children. J Urol. 2013;190:1468-1473. doi:10.1016/j.juro.2013.01.004

14. Harraz AM, Taha DE, Shalaby I, Hafez AT. Evaluation of factors predicting recoverability of renal function after pyeloplasty in adults. Urol Int. 2014;93(4):403-405. doi:10.1159/000357625

15. Brennan S, Watson D, Schneider M, Rudd D, Kandasamy Y. Can measurement of the foetal renal parenchymal thickness with ultrasound be used as an indirect measure of nephron number? J Dev Orig Health Dis. 2021;12(2):184-192. doi:10.1017/S204017442000015X

16. Brennan S, Schneider M, Watson D, Kandasamy Y, Rudd D. The renal parenchyma-evaluation of a novel ultrasound measurement to assess fetal renal development: protocol for an observational longitudinal study. BMJ Open. 2017;7(12):e019369. doi:10.1136/bmjopen-2017-019369
17. Huang WY, Peters CA, Zurakowski D, et al. Renal biopsy in congenital ureteropelvic junction obstruction: evidence for parenchymal maldevelopment. Kidney Int. 2006;69(1):137-143. doi:10.1038/sj. ki.5000004

18. Han JH, Song SH, Lee JS, et al. Best ultrasound parameter for prediction of adverse renal function outcome after pyeloplasty. Int J Urol. 2020;27(9):775-782. doi:10.1111/iju.14299

19. Almodhen F, Jednak R, Capolicchio JP, Eassa W, Brzezinski A, ElSherbiny M. Is routine renography required after pyeloplasty? J Urol. 2010;184(3):1128-1133. doi:10.1016/j.juro.2010.05.017

20. Paraboschi I, Mantica G, Dalton NR, Turner C, Garriboli M. Urinary biomarkers in pelvic-ureteric junction obstruction: a systematic review. Transl Androl Urol. 2020;9(2):722-742. doi:10.21037/ tau.2020.01.01

21. Jackson L, Woodward M, Coward RJ. The molecular biology of pelvi-ureteric junction obstruction. Pediatr Nephro. 2018;33 (4):553-571. doi:10.1007/s00467-017-3629-0

\section{Publish your work in this journal}

Research and Reports in Urology is an international, peer-reviewed, open access journal publishing original research, reports, editorials, reviews and commentaries on all aspects of adult and pediatric urology in the clinic and laboratory including the following topics: Pathology, pathophysiology of urological disease; Investigation and treatment of urological disease; Pharmacology of drugs used for the treatment of urological disease. The manuscript management system is completely online and includes a very quick and fair peer-review system, which is all easy to use. Visit http://www.dovepress.com/ testimonials.php to read real quotes from published authors. 